\title{
9.2 Surfaces' roughness of composite bearings based on grinding waste for printing machines units at fine cubonite grinding
}

The development of the printing industry requires the creation of such machines, which must provide high requirements for the parameters of their reliability and, above all, to high wear resistance, durability and maintainability. The speeds of the working bodies are constantly increasing when the parts' rotational speeds of the friction pairs reach the level of 800-1000 rpm and above, and the load increases to 5.0 - 7.0 MPa. This leads to the appearance of friction temperatures from 300 to $500^{\circ} \mathrm{C}$ on the working surfaces, which creates extreme conditions for the operation of printing machines [550557]. Such conditions require special approaches to ensure the reliability of printing equipment and increase its maintainability.

So, according to the data of the largest in Ukraine State Publishing House "Press of Ukraine", the service life of sliding bearings made of cast bronze BrAZh9-4 is only 0.5-1.0 years in the friction units of printing machines KBA Rapida - 105, "PLAMAG Rondest RO 170", "STAR BINDER 1509", etc., which operate at high speeds and increased loads. Such service life is associated with the imperfection of existing technologies for the manufacture of plain bearings and their subsequent finishing [550557].

Requirements for friction parts' surfaces high quality are constantly increasing. These are due to the continuous increase in important operating parameters of printing equipment and, above all, lengthen of parts service life, mechanisms and machines in general.

Recently, new bearing composite materials based on grinding waste of alloyed tool steels 7HG2VMF, $86 \mathrm{H} 6 \mathrm{NFT}$ and others with $\mathrm{CaF}_{2}$ solid lubricant additives were synthesized to significantly increase the service life of friction units in rotary printing machines $[552,553]$. These are metal grinding wastes of machine-building and toolmaking industries, which are taken to the dump because of their abrasive contamination and are not used in the repeated cycle of production. Such specified waste contains a significant number of valuable alloying elements, such as $\mathrm{W}, \mathrm{Mo}, \mathrm{V}, \mathrm{Co}, \mathrm{Al}, \mathrm{Ti}, \mathrm{Cr}$, 
$\mathrm{Nb}$, etc. After proper processing, these wastes can be used in the further production cycle in particular for the production of effective slide bearings, as initiated by the authors [550, 552, 553]. The authors [550-557] developed a technology for the synthesis of new composite bearings from recycled raw materials, which also included a comprehensive technology for this waste regeneration.

Studies have demonstrated that the developed composite bearings based on steel grinding waste can be successfully operated at speeds up to $1000 \mathrm{rpm}$ and specific pressures up to $5 \mathrm{MPa}$ [550-557]. Whereas the friction processes analysis has shown that the wear rate of the friction surfaces is determined by the working surfaces' initial quality parameters.

However, the technological processes of finishing such new composite parts for printing machines are currently insufficiently studied.

Only recently the technological processes of working surfaces' fine abrasive grinding and magnetic abrasive processing (MAP) of sliding bearings made of new composites have been studied in detail and acquired normative regulations [558-561]. The MAP and fine abrasive grinding processes have been studied in sufficient detail from the point of view of optimizing the surface quality parameters [550, 558-560]. As a result of the performed research, important for the industry recommendations on the use of abrasive tools and processing modes were obtained, which guarantee obtaining the necessary surface quality parameters, such as surface roughness, depth and degree of hardening, distortion of the second kind, values of residual stresses and depth of their location near the surface layer. These characteristics should provide the necessary service life and durability of new composite bearings based on grinding waste for printing machines.

It should be noted that the studies were performed taking into account the concurrent processes that accompany the fine chips cutting with abrasive grain from the surface. Namely, the surface layer's strengthening due to the force field (cutting forces components $\mathrm{Px}, \mathrm{Py}, \mathrm{Pz}$ ) and the subsequent "rest" phenomenon of the surface layers distorted by the cutting forces under the instantaneous contact temperatures $\mathrm{T}^{\circ} \mathrm{C}$ action were taken into account $[550,558-560]$. 
Based on the performed research it was proved that the further improving the surfaces quality of new bearings it is possible only by application of the superfine abrasive processing such as cubonite grinding processes.

Unfortunately, the fine cubonite grinding processes of new self-lubricating composite bearings based on tool steels grinding waste with $\mathrm{CaF}_{2}$ solid lubricant additions have not been sufficiently studied.

Today there is enough information on the use of fine grinding for special difficultto-machine materials using grinding tools based on cubic boron nitride CBN (KNBcubonite, domestic abbreviation) in the scientific and technical literature [558, 559]. These data illustrate the high quality parameters of the processed surfaces due to the cutting properties of cubonite [558, 559].

Scientists and practitioners of leading machine-building enterprises have proven that the use of cubonite tools allows obtaining surface quality parameters that are not inferior to those obtained using honing.

However, the cubonite grinding processes of bearings made of new high-alloy wear-resistant composite materials still remain unexplored.

The lack of clear recommendations for fine cubonite grinding of difficult-toprocess and high-alloy composite materials leads to an increase in the number of technological grinding schemes, which are not always optimal. This requires from scientists and practitioners to comprehensively investigate the fine cubonite grinding processes of plain bearings made of new composite materials based on tool steels grinding waste, and on this basis to create typical technological processes for printing engineering that illustrates the relevance of the research topic.

The objective of this work was to study the surface roughness parameters at fine cubonite grinding of new self-lubricating composite bearings based on 7HG2VMF and 86H6NFT regenerated tool steels grinding waste with $\mathrm{CaF}_{2}$ solid lubricant additives, and to establish the influence of the grinding wheel's grain size, the type of tool bond and the main cutting modes on the new composite bearings' surface quality parameters.

The objects of the study were the fine cubonite grinding processes and their influence on the quality parameters of the composite bearings' working surfaces. 
The subject of the study were samples of self-lubricating composite bearings based on 7HG2VMF and $86 \mathrm{H} 6 \mathrm{NFT}$ steels grinding waste with $\mathrm{CaF}_{2}$ solid lubricant additives. Experimental studies were performed according to the method [558-560], the results of which have been presented in Table 1.

Table 1.

Roughness parameter $\mathrm{Ra}$ for fine cubonite grinding of bearing composite material $7 \mathrm{HG} 2 \mathrm{VMF}+5 \% \mathrm{CaF}_{2}[553]$

\begin{tabular}{|c|c|c|c|c|}
\hline \multirow{3}{*}{$\begin{array}{l}\text { Cross feed, } \\
\text { Scf, } \\
\mathrm{mm} / \text { double } \\
\text { stroke }\end{array}$} & \multirow{3}{*}{$\begin{array}{c}\text { Product speed } \\
\text { (longitudinal } \\
\text { feed), Vp, m/min }\end{array}$} & \multicolumn{3}{|c|}{ Grinding depth $\mathrm{t}, \mathrm{mm}$} \\
\hline & & 0.002 & 0.01 & 0.05 \\
\hline & & \multicolumn{3}{|c|}{$\mathrm{Ra}, \mu \mathrm{m}$} \\
\hline \multirow{3}{*}{0.1} & 2 & 0.269 & 0.347 & 0.680 \\
\hline & 5 & 0.319 & 0.396 & 0.714 \\
\hline & 10 & 0.325 & 0.418 & 0.860 \\
\hline \multirow{3}{*}{0.2} & 2 & 0.349 & 0.425 & 0.929 \\
\hline & 5 & 0.405 & 0.414 & 1.053 \\
\hline & 10 & 0.409 & 0.507 & 1.207 \\
\hline \multirow{3}{*}{0.5} & 2 & 0.536 & 0.788 & 1.570 \\
\hline & 5 & 0.621 & 0.874 & 1.793 \\
\hline & 10 & 0.645 & 0.950 & 1.015 \\
\hline \multirow{3}{*}{1.0} & 2 & 0.816 & 0.949 & 2.095 \\
\hline & 5 & 0.922 & 1.070 & 2.405 \\
\hline & 10 & 1.028 & 1.150 & 2.615 \\
\hline
\end{tabular}

Note: Machine - FF-350 "Abawerek" (Germany), abrasive - KBNM14Br on bakelite-rubber bond, wheel speed - $22 \mathrm{~m} / \mathrm{sec}$, processing - without cooling.

Data analysis Table 1 shows that the roughness parameter Ra changes with the change of the machining factors, namely, the grinding depth $t$, the cross feed Scf and the longitudinal feed Vp.

Processing of experiments using the Student's method showed that the studied aggregates are significantly different in the case of dependent variables for the processed samples at fixed values of two variables (eg, longitudinal feed-product speed $\mathrm{Vp}$, cutting depth $\mathrm{t}$ ) and a variable third value (eg, cross feed Scf).

Similar results were obtained when comparing any samplings for cross feeds of $0.1-1.0 \mathrm{~mm} /$ double stroke and product speeds of $2-10 \mathrm{~m} / \mathrm{min}$. When the difference between the compared samplings' feed rates and the difference between the product's 
speeds increases the difference between the tabular and calculated Student's distribution also increases.

This allows us to conclude that with fine cubonite grinding there is a relationship between the surface roughness parameter $R a$ and the cutting depth $t: \operatorname{Ra}=f(t)$, at $\operatorname{Scf}=$ const, $\mathrm{Vp}=$ const.

Using the mathematical statistics methods, it is easy to show that there is a relationship between the parameter $\mathrm{Ra}$ and the cross feed $\mathrm{Scf}$ when $\mathrm{Ra}=\mathrm{f}(\mathrm{t})$ at $\mathrm{t}=$ const and $\mathrm{Vp}=$ const.

A similar statistical relationship exists between the roughness parameters $\mathrm{Ra}$ and the product's speed $V p$ when $\mathrm{Ra}=\mathrm{f}(\mathrm{t})$ at $\mathrm{Scf}=$ const. and $\mathrm{t}=$ const.

A similar statistical relationship exists between the roughness parameters $\mathrm{Ra}$ and the product's speed $\mathrm{Vp}$ when $\mathrm{Ra}=\mathrm{f}(\mathrm{t})$ at $\mathrm{Scf}=$ const. and $\mathrm{t}=$ const.

The multiple correlation equations for pair dependences were obtained for pairs such as Ra - t; Ra - Scf; Ra - Vp; Scf - t; t - Vp; Scf - Vp.

The calculations show there is a close linear relationship between the factors $\mathrm{Ra}$, Scf, Vp and t. Formal mathematical analysis shows that between the factors Scf $-t ; t$ - Vp and Scf - Vp connection is absent.

The obtained correlation coefficients $r_{c}$ are far from 1. This indicates the roughness parameter $\mathrm{Ra}$ is influenced by other factors in addition to the factor for which $r_{c}$ was determined. The value of the correlation coefficients indicates the influence level of the studied factors on the surface roughness.

The multiple correlation equation for the studied factors has the form:

$$
\mathrm{Ra}=0.2595 \times \mathrm{Scf}+5.2 \times \mathrm{t}+0.0051 \times \mathrm{Vp}-0.047
$$

Analysis of formula (1) shows the cutting depth $t$ and the cross feed Scf have the greatest effect on the roughness parameter Ra, the product speed Vp the has the least effect.

This model accuracy can be improved by dividing the entire range of plane grinding modes into two groups:

$$
1^{\text {st }} \text { group: }
$$

- the cross feed Scf $=0.01-0.04 \mathrm{~mm} /$ double stroke; 
- the grinding depth $\mathrm{t}=0.002-0.01 \mathrm{~mm}$;

- the product speed $\mathrm{Vp}=2.0-5.0 \mathrm{~m} / \mathrm{min}$.

$2^{\text {nd }}$ group:

- the cross feed $\mathrm{Scf}=0.5-1.0 \mathrm{~mm} /$ double stroke;

- the grinding depth $\mathrm{t}=0.02-0.05 \mathrm{~mm}$;

- the product speed $\mathrm{Vp}=6.0-17.0 \mathrm{~m} / \mathrm{min}$.

After some transformations, equation (1) can be transformed and take the form: $1^{\text {st }}$ group:

$$
\mathrm{Ra}=0.2593 \times \mathrm{Scf}+5.22 \times \mathrm{t}+0.0051 \times \mathrm{Vp}-0.0037
$$

$2^{\text {nd }}$ group:

$$
\mathrm{Ra}=0.2593 \times \mathrm{Scf}+5.22 \times \mathrm{t}+0.0052 \times \mathrm{Vp}-0.054
$$

The Ra values calculated by formulas (2) and (3) differ from the experimental ones by $12-15 \%$, which allows us to use the formulas for practical calculations.

For example, knowing the specific values of Scf, $t$ and $\mathrm{Vp}$ for a specific abrasive tool, it is possible to approximately determine what the Ra parameter will be and evaluate the acceptability of the cubonite grinding selected modes in terms of the requirements for bearings.

The obtained conclusions are confirmed by fine cubonite grinding with the wheels of different grain size M50, M28, M14 and M7. The corresponding experimental data have been shown in Table 2 .

Table 2

Influence of tool grain size on the Ra surface roughness parameter at fine flat cubonite grinding of composite bearing blanks based on tool steel waste $[558,560]$

\begin{tabular}{|c|c|c|}
\hline \multirow{2}{*}{ Abrasive wheel } & \multicolumn{2}{|c|}{ Composition, wt. \% } \\
\cline { 2 - 3 } & 86H6NFT $+5 \% \mathrm{CaF}_{2}$ & 7HG2VMF $+5 \% \mathrm{CaF}_{2}$ \\
\cline { 2 - 3 } & \multicolumn{2}{|c|}{$\mathrm{Ra}, \mu \mathrm{m}$} \\
\hline KNB10Br1 & 0.894 & 0.905 \\
\hline KNB 5Br1 & 0.830 & 0.870 \\
\hline KNB 28Br1 & 0.248 & 0.778 \\
\hline KNB 20Br1 & 0.215 & 0.655 \\
\hline KNB 14Br1 & 0.195 & 0.209 \\
\hline KNB 10Br1 & 0.177 & 0.183 \\
\hline KNB 7Br1 & 0.159 & 0.162 \\
\hline
\end{tabular}




\begin{tabular}{|c|c|c|}
\hline $\begin{array}{c}\text { 63CM14G1 } \\
\text { (WGC14Gl) }\end{array}$ & 0.619 & 0.671 \\
\hline $\begin{array}{c}\text { 63CM7Gl } \\
\text { (WGC7Gl) }\end{array}$ & 0.360 & 0.362 \\
\hline
\end{tabular}

Note: Machine - FF-350 "Abawerk" (Germany); grinding modes: wheel speed $-22 \mathrm{~m} / \mathrm{sec}$, longitudinal feed (product speed) $-2 \mathrm{~m} / \mathrm{min}$; cross feed $0.1 \mathrm{~m} /$ double stroke; processing -without cooling.

Data analysis of Table 2 allows us to draw important practical conclusions that cubonite wheels with a grain size of $7 \mu \mathrm{m}$ provide the smallest surface roughness $\mathrm{Ra}$ in the investigated range of $7-100 \mu \mathrm{m}$ grain sizes for a cubonite tool. These results can be explained by the grinding theory general positions $[558,560,563]$.

An increase in surface roughness with an increase in grain size is due to an increase in the $\mathbf{a}_{\mathbf{z}}$ section of the metal layer cut.

The improvement of roughness with grain size minimization is explained by the fact that cubonite grains have a rather sharp shape (sharpening angle at the grain top) and the smallest rounding radius of a single grain in comparison with electrocorundum and monocorundum grains (Table 3 ).

Table 3 .

Average values of cutting grain angle geometry for different abrasive materials [9-13]

\begin{tabular}{|c|c|c|c|}
\hline \multirow[b]{2}{*}{$\begin{array}{l}\text { Abrasive } \\
\text { material }\end{array}$} & \multirow{2}{*}{$\begin{array}{c}\text { Abrasive } \\
\text { wheel, } \\
\text { foreign } \\
\text { analogue } \\
\text { (BS EN } \\
\text { 12413, BS } \\
\text { ISO 525) }\end{array}$} & \multicolumn{2}{|c|}{ Grain top geometry } \\
\hline & & $\begin{array}{c}\text { Rounding radius, } \\
\rho, \mu \mathrm{m}\end{array}$ & $\begin{array}{c}\text { Angle at the top, } \\
\text { deg. }\end{array}$ \\
\hline $\begin{array}{c}\text { Natural diamond, } \\
\text { D }\end{array}$ & $\begin{array}{c}\text { A10/8 } \\
\text { A6/5 } \\
\text { AM14/10 } \\
\text { (WD10; } \\
\text { WD6; } \\
\text { WD14) }\end{array}$ & $\begin{array}{l}2.8 \\
2.3 \\
1.6\end{array}$ & $\begin{array}{l}78.1 \\
73.3 \\
70.2\end{array}$ \\
\hline
\end{tabular}




\begin{tabular}{|c|c|c|c|}
\hline $\begin{array}{l}\text { Synthetic } \\
\text { diamond } \\
\text { SD }\end{array}$ & $\begin{array}{c}\text { AS10/8 } \\
\text { AS6/5 } \\
\text { ASM14/10 } \\
\text { (WSD10; } \\
\text { WSD6; } \\
\text { WSDM14) }\end{array}$ & $\begin{array}{c}2.2 \\
1.1 \\
0.7-0.8\end{array}$ & $\begin{array}{l}57.4 \\
52.2 \\
49.5\end{array}$ \\
\hline $\begin{array}{l}\text { Cubic boron } \\
\text { nitride, KBN } \\
\quad(\mathrm{CBN})\end{array}$ & $\begin{array}{c}\text { KNB10/8 } \\
\text { KNB6/5 } \\
\text { KNBM14/10 } \\
\text { (WCBN10; } \\
\text { WCBN6; } \\
\text { WCBN14) } \\
\end{array}$ & $\begin{array}{c}2.5 \\
1.3 \\
0.9-1.1\end{array}$ & $\begin{array}{l}59.0 \\
54.0 \\
51.0\end{array}$ \\
\hline $\begin{array}{l}\text { Green silicon } \\
\text { carbide, GC }\end{array}$ & $\begin{array}{c}\text { 63S10 } \\
63 \mathrm{SM} 28 \\
63 \mathrm{SM} 14 \\
\text { (WGC10; } \\
\text { WGC28; } \\
\text { WGC14) }\end{array}$ & $\begin{array}{l}7.5 \\
2.3 \\
2.0\end{array}$ & $\begin{array}{l}95.1 \\
92.1 \\
90.6\end{array}$ \\
\hline $\begin{array}{c}\text { White } \\
\text { electrocorundum, } \\
23 \mathrm{~A}\end{array}$ & $\begin{array}{c}23 \mathrm{~A} 10 \\
23 \mathrm{AM} 28 \\
23 \mathrm{AM} 14 \\
\text { (W23A10; } \\
\text { W23A28; } \\
\text { W23A14) }\end{array}$ & $\begin{array}{l}9.5 \\
2.7 \\
2.4\end{array}$ & $\begin{array}{l}98.3 \\
94.7 \\
92.5\end{array}$ \\
\hline
\end{tabular}

As a result of experimental data mathematical processing, a correlation equation was obtained for the relationship between the roughness parameter Ra and the grain size A for a tool made of KNB cubic boron nitride, which has the form:

$$
\mathrm{Ra}=0,0053 \mathrm{~A}-0,0071
$$

Thus, knowing the cubonite wheel grain size A, we can calculate the roughness parameter $\mathrm{Ra}$ and make sure the selected tool will ensure the requirements for the quality of the plain bearings' working surfaces.

This greatly simplifies the grinding tool rational choice in the development of technological processes.

It was also important to establish the influence of the abrasive wheel bond type on the new composites' surface roughness parameter $\mathrm{Ra}$ in addition to studies of the abrasive tool grain size influence. The results of this study have been shown in Table 4. 
Table 4.

Influence of cubonite wheel's bonding material on the surface roughness parameter $\mathrm{Ra}$ of composite samples $86 \mathrm{X} 6 \mathrm{H} \Phi \mathrm{T}+5 \% \mathrm{CaF}_{2}$ during flat grinding.

\begin{tabular}{|c|c|c|}
\hline $\begin{array}{c}\text { Abrasive tool } \\
\text { characteristics }\end{array}$ & Wheel's bonding material & $\begin{array}{c}\text { Roughness parameter } \\
\mathrm{Ra}, \mu \mathrm{m}\end{array}$ \\
\hline KNB5B1 & Bakelite B1 & 0.918 \\
KNB5Br1 & Bakelite-rubber Br1 & 0.850 \\
KNB5K1 & Ceramic K1 & 1.201 \\
KNB5M1 & Metal M1 & 1.179 \\
\hline KNBM28B1 & Bakelite B1 & 0.289 \\
KNBM28Br1 & Bakelite-rubber Br1 & 0.245 \\
KNBM28K1 & Ceramic K1 & 0.485 \\
\hline KNBM14B1 & Bakelite B1 & 0.225 \\
KNBM14Br1 & Bakelite-rubber Br1 & 0.195 \\
KNBM14K1 & Ceramic K1 & 0.370 \\
\hline KNBM10Br1 & Bakelite-rubber Br1 & 0.175 \\
\hline KNBM7Br1 & Bakelite-rubber Br1 & 0.157 \\
\hline
\end{tabular}

Note: Machine FF-350 "Abawerk" (Germany); grinding modes: wheel speed $-22 \mathrm{~m} / \mathrm{sec}$, longitudinal feed (product speed) $-2 \mathrm{~m} / \mathrm{min}$; cross feed $0.1 \mathrm{~m} /$ double stroke; processing -without cooling.

Analyzing the data in Table 4, it is seen that the best values of the surfaces' roughness parameters Ra provide cubonite wheels on the bakelite-rubber bond $\mathrm{Brl}$ at the fine grinding of the bearings made of new composites based on tool steels waste. This can be explained by its greater elasticity. Therefore, at the cutting of the cutting grain into the metal, each grain is damped in the direction of the resilient-elastic bonding material under the action of the cutting forces components during grinding. This causes an actual reduction in cutting depth. Therefore, the conditions for the formation of the surface roughness change and, as a consequence, the roughness parameter Ra decreases. This parameter is one of the most important factors that characterizes the surface quality after fine cubonite grinding and contributes to a significant increase in wear resistance and friction pair reliability [558-562]. 
The above conclusions are made based on the analysis of the actual data received at the experimental research with use of bonds wide range (bakelite, ceramic, metal, bakelite-rubber) and a cubonite wheel granularities of 100,28, 10 and $7 \mu \mathrm{m}$.

Taking into account that the physical phenomena in the process of metal cutting are fundamentally similar for flat, outer round and inner round grinding, experimental studies of fine cubonite grinding were performed taking into account the above results.

Thus, for experiments, only KNB cubonite tools with a grain size of 14-28 $\mu \mathrm{m}$ were used, which were formed into grinding wheels by a bakelite-rubber bond $\operatorname{Br} 1$.

External fine round grinding was performed on a precision machine AS-250 "Werkzojt" (Germany), and for internal grinding the precision internal-grinding machine of ultra-high precision SS-125 "Studder" (Switzerland) was used.

The main results of the study at the fine round external cubonite grinding and fine round internal grinding have been presented in Fig. 1, 2 for the bearing composite $86 \mathrm{H} 6 \mathrm{NFT}+5 \% \mathrm{CaF}_{2}$ based on steel grinding waste.

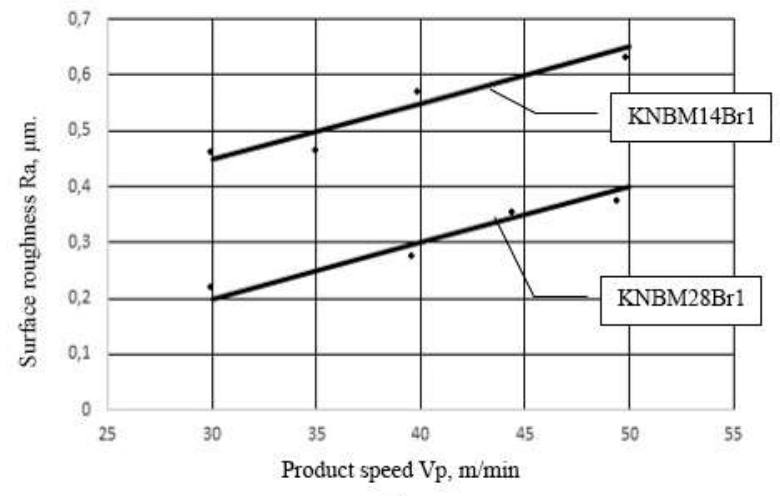

a)

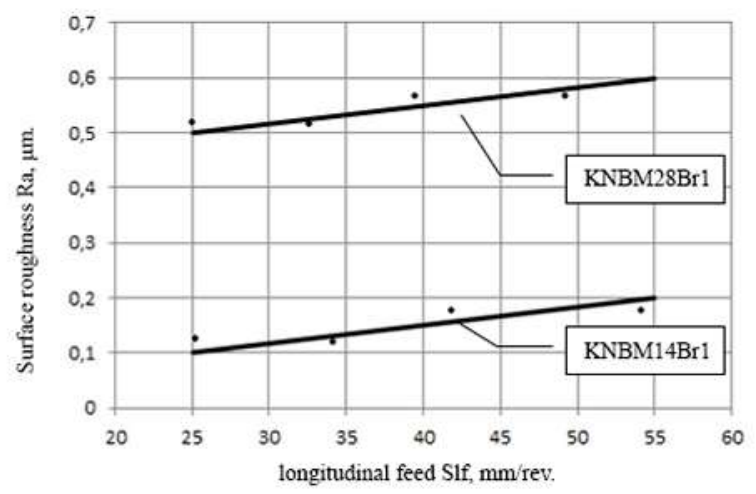

b)

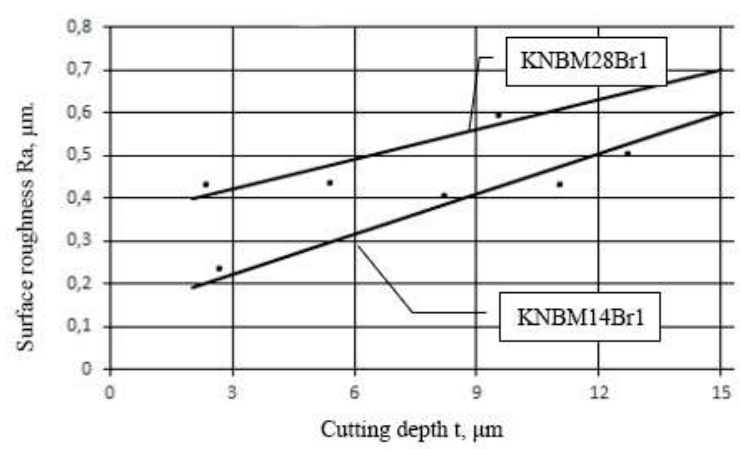

c)

Figure 1. Dependence of surface roughness parameters $\mathrm{Ra}$ on the modes of fine cubonite grinding $\mathrm{Vp}, \mathrm{S}_{\mathrm{lf}}$ and $\mathrm{t}$ at external round grinding (cubonite wheel speed - $\mathrm{Vw}$ $=35 \mathrm{~m} / \mathrm{sec}$ ): a) $\mathrm{S}_{\text {lf }}=5 \mathrm{~mm} / \mathrm{rev}$; $\mathrm{t}=2 \mu \mathrm{m}$; b) $\mathrm{Vp}=30 \mathrm{~m} / \mathrm{min} ; \mathrm{t}=2 \mu \mathrm{m}$; $) \mathrm{Vp}=30$ $\mathrm{m} / \mathrm{min} ; \mathrm{S}_{\text {lf }}=5 \mathrm{~mm} / \mathrm{rev}$. 
Experiments analysis shows (Fig. 1) the speed of the product Vp, longitudinal feed $S_{\text {If, }}$ cutting depth $t$, abrasive grain size and the cubonite tool bond composition most affect the surface roughness of new composite materials at a fine outer round cubonite grinding.

Similarly to flat cubonite grinding, the best surface quality (high roughness parameter $\mathrm{Ra}$ ) for fine round external cubonite grinding of composite cylindrical parts is provided by the use of tools based on $\mathrm{KNB}$ cubonite on a bakelite-rubber bond $(\mathrm{Br} 1)$ with a grain size of $14-28 \mu \mathrm{m}$ (M14- M28) and the fine grinding modes application such as $\mathrm{Vb} \rightarrow$ min; $\mathrm{Sp} \rightarrow$ min; $\mathrm{t} \rightarrow$ min.

Analogous results were obtained at a fine round internal cubonite grinding of the plain bearings' working surfaces from new composite materials based on tool steels waste (Fig. 2).

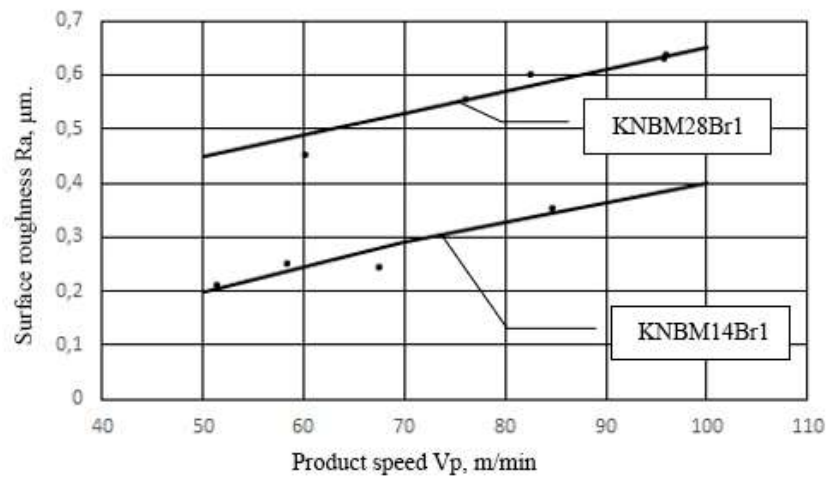

a)

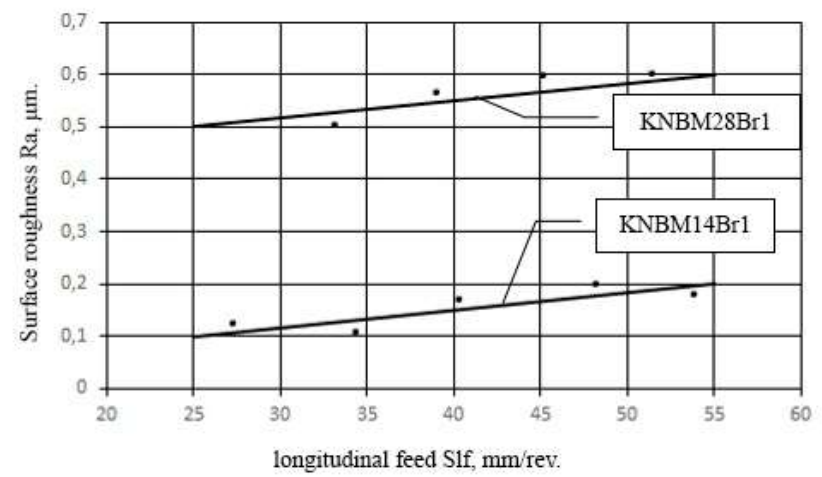

b)

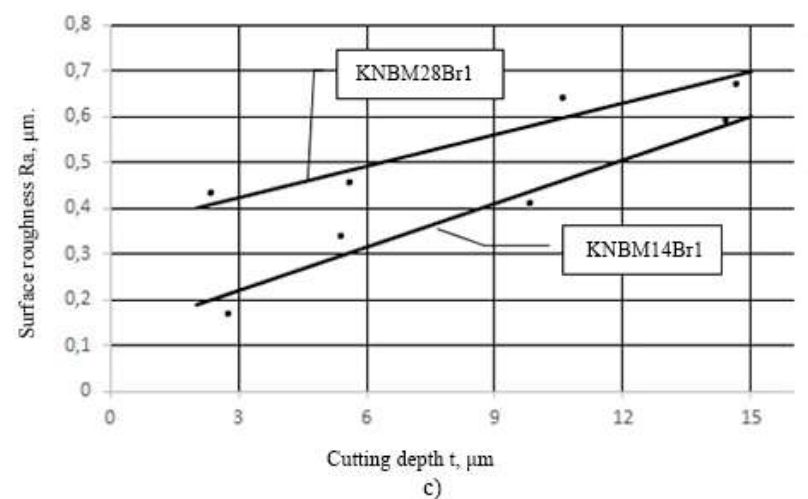

Figure 2. Dependence of surface roughness parameters $\mathrm{Ra}$ on the modes of fine cubonite grinding $\mathrm{Vp}, \mathrm{S}_{\mathrm{lf}}$ and $\mathrm{t}$ at internal round grinding (cubonite wheel speed - Vw $=50 \mathrm{~m} / \mathrm{sec}$ ): a) $\mathrm{S}_{\text {lf }}=30 \mathrm{~mm} / \mathrm{rev}$; $\left.\left.\mathrm{t}=2 \mu \mathrm{m} ; \mathrm{b}\right) \mathrm{Vp}=50 \mathrm{~m} / \mathrm{min} ; \mathrm{t}=2 \mu \mathrm{m} ; \mathrm{c}\right) \mathrm{Vp}=50$ $\mathrm{m} / \mathrm{min} ; \mathrm{Slf}_{\mathrm{f}}=30 \mathrm{~mm} / \mathrm{rev}$. 
The Fig. 2 analysis shows the depth of cutting $\mathbf{t}$, the longitudinal feed $\mathrm{S}_{\text {If }}$ and the part's rotation speed $\mathbf{V} \mathbf{p}$ have the greatest influence on the surface roughness parameter $\mathrm{Ra}$ during round internal cubonite grinding of composite parts using cubonite KNB wheels with a grain size of $14-28 \mu \mathrm{m}$ on bakelite-rubber bond $\mathrm{Br}$.

Summarizing the complex of the performed studies, it is necessary to draw important scientific and practical conclusions.

1. The features of fine cubonite grinding of new composite bearings based on utilized and regenerated tool steels grinding waste have been investigated.

2. It is shown the main regularities coincide with flat, round external and internal cubonite grinding of new composite parts.

3. It is proved the grain size, the material of the cubonite wheel and the fine cubonite grinding modes significantly affect the surface roughness parameter Ra.

4. It is shown the best roughness parameters $\mathrm{Ra}$ are provided with the use of cubonite grinding wheels (CBN) with a grain size of $14-28 \mu \mathrm{m}$ on a bakelite-rubber bond and the following cutting modes, namely:

- for flat cubonite grinding: wheel speed $-22 \mathrm{~m} / \mathrm{sec}$, longitudinal feed $-2 \mathrm{~m} / \mathrm{min}$, cross feed $-0.1 \mathrm{~mm} /$ double stroke and cutting depth $-2 \mu \mathrm{m}$;

- for external round cubonite grinding: wheel speed $-30-45 \mathrm{~m} / \mathrm{sec}$, product speed-30 $\mathrm{m} / \mathrm{min}$, longitudinal feed $-30 \mathrm{~mm} / \mathrm{rev}$, cross feed $-0.1 \mathrm{~mm} /$ double stroke and cutting depth $-2 \mu \mathrm{m}$;

- for internal round cubonite grinding: wheel speed $-40-45 \mathrm{~m} / \mathrm{sec}$, longitudinal feed $-50 \mathrm{~m} / \mathrm{min}$, cross feed $-30 \mathrm{~mm} / \mathrm{rev}$ and cutting depth $-2 \mu \mathrm{m}$.

5. The obtained results show the use of cubonite grinding provides the working surfaces' high quality of new composite bearings based on regenerated tool steels grinding waste, increases wear resistance, durability and stability of rotary printing machines' friction units. 